Authors' Contribution: A Study Design B Data Collection C Statistical Analysis D Data Interpretation E Manuscript Preparation F Literature Search G Funds Collection

\section{Still unnoticed. Women in Polish sports associations. Content analysis of Polish, international, and British formal rules of sports organizations}

\author{
Natalia Organista \\ Department of Philosophy and Sociology, Józef Piłsudski University of Physical Education \\ in Warsaw, Poland
}

\title{
abstract
}

Background

Material/Methods

Results

Conclusions

Key words

\section{article details}

Article statistics

Full-text PDF:

Copyright

Indexation:

Funding:

Conflict of interest: Corresponding author:

Open Access License:
From a critical paradigm point of view sport has been a sexist institution. Despite the women empowerment in sport they are still trivialized and marginalized. Research also shows that sport organizations may be exceptionally opposed to women, valuing hegemo nic masculinity.

Therefore, the aim of this article is to check whether gender inequalities occur in Polish sports organizations and what the scale of those inequalities is in comparison to international and British organizations. Content analysis was used to examine official documents of organizations. The sample consists of seventeen Polish, international and British sports organizations.

The content analysis indicates that international and British organizations place more pressure on preventing discrimination by using appropriate provisions in the statutes, reserving places for women in committees or paying attention to the language used in documents.

The findings revealed that Polish sports organizations do not implement the strategy to reduce the degree of discrimination due to gender. They remain blind to issues connected with gender.

sport organizations, gender, content analysis, Polish, British, international sport organizations

Word count: 6,809; Tables: 3; Figures: 0; References: 28

Received: January 2016; Accepted: December 2016; Published: March 2017

http://www.balticsportscience.com

(๑) Gdansk University of Physical Education and Sport, Poland

AGRO, Celdes, CNKI Scholar (China National Knowledge Infrastructure), CNPIEC, De Gruyter - IBR (International Bibliography of Reviews of Scholarly Literature in the Humanities and Social Sciences), De Gruyter - IBZ (International Bibliography of Periodical Literature in the Humanities and Social Sciences), DOAJ, EBSCO - Central $\&$ Eastern European Academic Source, EBSCO - SPORTDiscus, EBSCO Discovery Service, Google Scholar, Index Copernicus, J-Gate, Naviga (Softweco, Primo Central (ExLibris), ProQuest - Family Health, ProQuest - Health \& Medical Complete, ProQuest - Illustrata: Health Sciences, ProQuest - Nursing \& Allied Health Source, Summon (Serials Solutions/ProQuest, TDOne (TDNet), Ulrich's Periodicals Directory/ulrichsweb, WorldCat (OCLC)

\section{sectors.}

Author has declared that no competing interest exists.

Dr. Natalia Organista, University of Physical Education Warsawa - Department of Philosophy and Sociology, Marymoncka 34, Warszawa 00-968, Poland; e-mail: natalia.organista@gmail.com

This is an open access article distributed under the terms of the Creative Commons Attribution-Non-commercial 4.0 International (http://creativecommons.org/licenses/by-nc/4.0/), which permits use, distribution, and reproduction in any medium, provided the original work is properly cited, the use is non-commercial and is otherwise in compliance with the license. 


\section{INTRODUCTION}

Sports are a global practice that is extremely important due to its commercial and economic dimensions. Sports also constitute a primarily male enterprise, and while this state of affairs is changing, the historical heritage of sports belongs to men [1]. Sports exemplify one of many cultural practices that shape masculinity and femininity [2]. Messner and Dworkin put forward the thesis that in addition to its commercial aim, the primary aim of sports is to maintain the traditionally understood masculinity and femininity $[3,4]$. Sports stabilize the theories of the "natural" differences between sexes and the resulting sex-based hierarchy. Many publications on the shaping of masculinity and femininity in sports point out that sports constitute the means through which hegemonic masculinity is reproduced [5]. Taking into account that physicality is the fundamental source of the interpretation of femininity and masculinity, sports become one of the social institutions wherein the role of the body in upholding relationships between genders can be the most readily observed. Strength, endurance, and perfect training uphold the traditional notion of masculinity [6]. The feminist paradigm in the research on sport indicates that women's sports achievements are compared to the masculine model, which hampers the autonomy of women's sports and marginalizes and trivializes them [7].

Furthermore, many studies show that women's positions in the employment market are worse than men's [8]. Connell points out the phenomenon of gendered labor stemming from the culturally grounded division into the public sphere and the private sphere. The division constitutes the structural basis of gender relations in Western societies. Each sphere generates a different understanding of femininity and masculinity and is governed by different social relations [9]. These differences lead to varying experiences between women and men. Acker coined the term gendered institutions, showing that these institutions used to be blind to the matters of gender, which led to incorrect interpretations of their activity [10]. The absence of women became a trait that shaped these institutions. In turn, gender is the principal part of an organization. It determines the distribution of power and produces gender-based models and rules further enhanced by particular symbolism $[11,12]$. One of such models is the belief that masculinity is tied to leadership and expert knowledge. The concept of "masculine" and "feminine" styles of management is widely discussed. Juxtaposing the subject of discrimination of women in organizations according to the "think manager, think masculine" [13] rule and the notion of sports as a masculine enterprise leads to the conclusion that sports organizations may be exceptionally opposed to women, valuing hegemonic masculinity and the resulting practices related to power and privileges $[14,15]$. Gender-based segregation is exacerbated by the fact that men and women participate in separate sports competitions, the belief that sports are important, and, first and foremost, by the use of team games as a means of socialization for boys $[16,17,18]$. Furthermore, coming to the realization that sports organizations operate according to a certain structure is made difficult by a lack of knowledge about cultural codes and gender-based characteristics of professional work and sports themselves [19, 20, 21, 22, 23]. 


\section{MATERIALS AND METHODS}

The aim of the study was to analyze and compare the formal regulations of Polish, international, and British sports organizations. Content analysis was used to examine information from official documents of the organization. The documents provided by the organizations reflect their official standpoint on many issues, including gender equality and the recognition and prevention of gender inequality. Analysis of legal acts allows the normative framework of social life to be described. Knowledge on this framework is required to enable the understanding of the functioning and internal practices of such organizations. Research was conducted on a purposive sample comprising 17 Polish, 17 British, and 17 international sports organizations. These organizations represent team, individual, collision, contact and non-contact sports, including those commonly regarded as masculine or feminine. The organizations are the largest ones in their respective countries and represent the most popular disciplines in a given cultural circle. The research was conducted in 2014.

The following issues were investigated: whether official documents contain prohibitions against gender discrimination, whether the sports organizations aim to decrease the disproportion (if any) between the number of employed men and women through special provisions, and whether the documents contain provisions that promote supporting and developing women's sports as part of the functioning of the organization. Whether the official documents of the organizations avoid the use of sexist language was also investigated.

\section{RESULTS}

\section{CONTENT ANALYSIS OF THE FORMAL REGULATIONS OF POLISH AND INTERNATIONAL SPORTS ORGANIZATIONS ACCORDING TO GENDER}

Analysis of official documents of Polish, international, and British sports organizations provides information about the attitude of these organizations toward the issue of gender equality in sports. Sources of information about the recognition of gender inequality in sports comprise statutes, sport regulations, competition regulations, codes of conduct, and individual strategies. These documents indicate not only whether women are protected by particular provisions, but what strategies are applied to ensure equal treatment of women and men in sports as well. The conducted analysis involved determining whether the official documents contain prohibitions against gender discrimination. Such provisions indicate whether a given organization is aware of the issue of gender inequality in sports. It should be noted that, rather than any strategies for equalizing the chances for women and men in sports (i.e., positive actions), this concerns a clear opposition to gender discrimination. Provisions emphasizing support for women's sports, which rarely appear in the documents of the organizations, were also analyzed. Provisions about support for women's sports are important because they show whether a given organization recognizes the issue of the marginalization of women's sports (the historical and cultural heritage of sport as the domain of men) and aims to counteract it. Furthermore, it was determined whether the organizations use quotas for the minority groups in a given body. Quotas are the most well-known means of increasing the number of women in the decision-making bodies of many social organizations. A quota of $30-40 \%$ is considered to provide a real 
benefit in a given environment and prevent the tokenization of women. An appropriate number of positions in a given body is allocated to women based on the assumption that without a significant number of women holding important public positions, the culture of sports organizations cannot become equalitybased, and the aims and functioning of organizations cannot be reshaped to benefit also women $[24,25]$. The final subject of analysis was linguistic sexism. Based on the assumption that women are depreciated through language by being ignored or excluded (use of masculine pronouns only, masculine names of professions, etc.), it was considered important to investigate whether the language used in the official documents of sports organizations recognizes women as a subject of consideration [26].

\section{CONTENT ANALYSIS OF FORMAL REGULATIONS OF SPORTS ORGANIZATIONS REGARDING THE PRESENCE OF PROVISIONS PROHIBITING GENDER DISCRIMINATION}

Only the documents of three Polish sports organizations (PZB, PZHL, and PZPN) include a prohibition against gender discrimination (Table 1).

"Discrimination stemming from such reasons as gender, origin, skin color, language, religion, political and other views and national and social origin is strictly prohibited and is subject to disciplinary action in accordance with the disciplinary regulations" (Section 4 of the Statute of PZB).

Table 1. Analysis of official documents of Polish sports organizations in terms of provisions about maintaining gender equality

\begin{tabular}{|c|c|c|c|c|c|}
\hline $\begin{array}{c}\text { Name of } \\
\text { organization }\end{array}$ & $\begin{array}{l}\text { Prohibition } \\
\text { against gender } \\
\text { discrimination }\end{array}$ & $\begin{array}{c}\text { Gender-sensitive } \\
\text { language }\end{array}$ & $\begin{array}{l}\text { Provisions on } \\
\text { quotas for } \\
\text { women } \\
\text { in the bodies } \\
\text { of the } \\
\text { organization }\end{array}$ & $\begin{array}{c}\text { Provisions on } \\
\text { supporting and } \\
\text { developing } \\
\text { women's sports }\end{array}$ & $\begin{array}{l}\text { Provisions on } \\
\text { quotas for } \\
\text { women } \\
\text { in the cells } \\
\text { of the } \\
\text { organization }\end{array}$ \\
\hline PZB & true & false & false & $\begin{array}{l}\text { women's } \\
\text { and men's }\end{array}$ & false \\
\hline PZG & false & false & false & $\begin{array}{l}\text { women's } \\
\text { and men's }\end{array}$ & false \\
\hline PZHL & true & false & false & $\begin{array}{l}\text { women's } \\
\text { and men's }\end{array}$ & false \\
\hline PZJ & false & false & false & false & false \\
\hline PZKosz & false & false & false & false & false \\
\hline PZN & false & false & false & false & false \\
\hline PZPC & false & false & false & true & false \\
\hline PZPN & true & false & false & false & false \\
\hline PZPS & false & false & false & false & false \\
\hline PZR & false & false & false & false & false \\
\hline PZSWIM & false & false & false & false & false \\
\hline PZZ & false & false & false & true & false \\
\hline PZŻ & false & false & false & false & false \\
\hline ZPRP & false & false & false & false & false \\
\hline PZLA & false & false & false & false & false \\
\hline PZKol & false & false & false & false & false \\
\hline PZT & false & false & false & false & false \\
\hline
\end{tabular}

PZB - Polish Boxing Association; PZG - Polish Gymnastics Association; PZHL - Polish Ice Hockey Association; PZJ- Polish Judo Association; PZKosz - Polish Basketball Association; PZN - Polish Ski Association; PZPC - Polish Weightlifting Association

The other 14 Polish sports organizations include no prohibition against gender discrimination in any of their documents. The absence of such provisions is thought provoking, at the least because Polish organizations belong to international sports organizations, which in turn have provisions prohibiting 
gender discrimination. The analyzed statutes include provisions stating that Polish organizations are part of international organizations.

1. "The Association operates in accordance with this statute (hereinafter referred to as (Statute'), regulations of the Association Authorities, the statute of the International Association of Athletics Federations (hereinafter referred to as 'IAAF'), and in respect to and within the legal regulations in force" (Section 3 of the Statute of the Polish Athletic Association)".

All analyzed international sports organizations have provisions prohibiting gender discrimination and promoting a neutral worldview in their primary document, i.e. their statute or constitution.

3. Discrimination of any kind against a country, private person or group of people on account of ethnic origin, gender, language, religion, politics or any other reason is strictly prohibited and punishable by suspension or expulsion (Status FIFA 2012, General provision).

Table 2. Analysis of official documents for international sports organizations in terms of provisions stipulating gender equality

\begin{tabular}{|c|c|c|c|c|c|}
\hline $\begin{array}{c}\text { Name of } \\
\text { organization }\end{array}$ & $\begin{array}{l}\text { Prohibition } \\
\text { against } \\
\text { gender } \\
\text { discrimination }\end{array}$ & $\begin{array}{c}\text { Gender- } \\
\text { sensitive } \\
\text { language }\end{array}$ & $\begin{array}{l}\text { Provisions on } \\
\text { supporting } \\
\text { and developing } \\
\text { women's sports }\end{array}$ & $\begin{array}{l}\text { Provisions on } \\
\text { quotas for women } \\
\text { in the bodies of } \\
\text { the organization }\end{array}$ & $\begin{array}{l}\text { Provisions on allo- } \\
\text { cating } \\
\text { positions for women } \\
\text { in the bodies of the } \\
\text { organization }\end{array}$ \\
\hline IWF & true & true & true & false & true \\
\hline AIBA & true & false & true & false & false \\
\hline FIVB & true & true & true & false & true \\
\hline FIBA & true & false & true & false & true \\
\hline IAAF & true & true & true & false & true \\
\hline FIFA & true & false & true & false & true \\
\hline FINA & true & true & true & false & false \\
\hline FIG & true & false & false & false & false \\
\hline $\mathrm{IIHF}$ & true & false & false & false & true \\
\hline IHF & true & false & false & false & false \\
\hline FILA & true & true & false & false & true \\
\hline IJF & true & false & false & false & false \\
\hline IRB & true & false & false & false & false \\
\hline ISAF & true & false & true & true & true \\
\hline FIS & true & false & false & false & false \\
\hline $\mathrm{UCl}$ & true & false & true & false & false \\
\hline ITF & true & false & false & false & false \\
\hline
\end{tabular}

IWG - International Weightlifting Federation - IWF; AIBA - Association Internationale de Boxe Amateur; FIVB - Fédération Internationale de Volleyball; FIBA - Federation de Internationale de basketball; IAAF - International Association of Athletics Federations; FIFA - Federation Internationale de Football Association; FINA - Fédération Internationale de Natation; FIG - Federation Internationale de Gimnastique; IIHF - International Ice Hockey Federation; IHF - International Handball Federation; FILA - Fédération Internationale des Luttes Associées; IJF - International Judo Federation, IRB - International Rugby Board; ISAF - International Sailing Federation; FIS - Fédération Internationale de Ski; UCI - Union Cycliste Internationale; ITF - International Tennis Federation.

Analysis of British sports organizations also showed that most of them have regulations prohibiting gender discrimination (Table 3). These organizations prepared separate documents (Equality Policies) that regulate the issue of equality. 
Table 3. Analysis of official documents of British sports organizations in terms of provisions stipulating gender equality

\begin{tabular}{|c|c|c|c|c|c|}
\hline $\begin{array}{l}\text { British Sports } \\
\text { Organizations }\end{array}$ & $\begin{array}{l}\text { Prohibition } \\
\text { against } \\
\text { gender } \\
\text { discrimination }\end{array}$ & $\begin{array}{l}\text { Gender- } \\
\text { sensitive } \\
\text { language }\end{array}$ & $\begin{array}{l}\text { Provisions on } \\
\text { supporting and } \\
\text { development } \\
\text { women's sports }\end{array}$ & $\begin{array}{l}\text { Provisions on } \\
\text { quotas for } \\
\text { women } \\
\text { in the bodies of } \\
\text { the organization }\end{array}$ & $\begin{array}{l}\text { Provisions on allo- } \\
\text { cating positions for } \\
\text { women } \\
\text { in the bodies } \\
\text { of the organization }\end{array}$ \\
\hline $\mathrm{BS}$ & true & false & false & false & false \\
\hline BWL & true & false & false & false & false \\
\hline ABAE & false & false & false & false & false \\
\hline BVF & false & true & false & false & false \\
\hline GBB & true & false & false & false & false \\
\hline UKA & true & false & false & false & false \\
\hline FA & true & false & true & false & false \\
\hline BG & true & false & false & false & false \\
\hline $\mathrm{BIH}$ & true & true & false & false & true \\
\hline $\mathrm{EH}$ & true & true & false & false & false \\
\hline BWA & true & false & false & false & false \\
\hline BJ & true & true & false & false & false \\
\hline RFU & true & false & false & false & false \\
\hline RYA & true & false & false & false & false \\
\hline BSS & true & false & false & false & false \\
\hline$B C$ & true & false & false & false & false \\
\hline LTA & true & true & false & false & false \\
\hline
\end{tabular}

BS - British Swimming; BWL - British Weightlifting; ABAE - The Amateur Boxing Association of England; BVF - British Volleyball Federation, GBB - Great Britain Basketball, UKA - United Kingdom Athletics; FA - The Football Association; BG - British Gymnastics; BIH - British Ice Hokey; EH - English Handball Association; BWA - British Wrestling Association BJ - British Judo; RFU - Rugby Football Union; RYA - Royal Yachting Association; BSS - British Ski and Snowboard; BC British Cycling; LTA - Lawn Tennis Association.

Analysis of the aforementioned documents indicates that these organizations put considerable emphasis on the issue of gender equality. This is supported, e.g., by the fact that the documents, rather than being limited to provisions prohibiting gender discrimination, also include provisions prohibiting discrimination based on pregnancy or motherhood, i.e., situations that often cause women to leave sports and organizations to cancel employment and sponsorship agreements. Therefore, it is important to recognize the genderbased character of these situations. British sports organizations are also the only ones that prohibit sex change-based discrimination. Persons who have undergone gender reassignment are sometimes asked about their "real" gender. Moreover, a belief exists that they have undergone the operation to achieve better results in sports, and are thus discriminated against.

1.1. British Basketball (BB) is fully committed to the principles of equality of opportunity and is responsible for ensuring that no job applicants, staff (paid or unpaid), workers, office holders, volunteers, or participants (together "Stakeholders") are unlawfully discriminated against on the grounds of age, disability, gender reassignment, marriage and civil partnership, pregnancy and maternity, race, religion or belief, sex and sexual orientation (together the "Protected Characteristics") (1. Policy Objectives, Equality Policy British Basketball).

\section{CONTENT ANALYSIS OF FORMAL REGULATIONS OF SPORTS ORGANIZATIONS CONCERNING THE PRESENCE OF PROVISIONS ON SUPPORTING AND DEVELOPING WOMEN'S SPORTS}

The analyzed sports organizations differ in their responses to the issue of gender discrimination in sports. As shown in Tables 1, 2, and 3, regulations supporting women's sports rarely appear in the documents of the organizations. Provisions on supporting women's sports are important, as they are indicative of whether a given organization recognizes the issue of women's sports marginalization 
and intends to counteract it. Provisions of this kind are the most prevalent in the documents of international sports organizations.

As the UCI wishes to represent all those practicing cycling, it gives its constant attention to their specific needs, whether in relation to age (juniors, masters), gender (women's cycling), those with a handicap (cycling for riders with a disability) and cultural and social conditions (Rules of good governance UCI).

The UCI reaches these objectives respecting the principles that it believes to be fundamental. It guarantees to respect the equality of all parties placed under its authority, without racial, political, religious, or any other discrimination; in particular, the UCI encourages the development of women's cycling and, in co-operation with the International Paralympic Committee (IPC), promotes cycling for riders with a disability (Objectives, Rules of good governance UCI).

They often take the form of statements on supporting a given discipline regardless of age, gender, or race of the athletes.

4. To encourage participation in Athletics at all levels throughout the world regardless of age, gender or race (Article 3, Objects, Constitution IAAF).

FIFA presents separate documents about barriers encountered by women who wish to engage in soccer. In "Overcoming Cultural Barriers", FIFA lists particular issues encountered by women wishing to play soccer. In turn, "Increase participation and competitions", a document about increasing the participation of women in soccer training sessions and competitions, indicates the hitherto unused potential of and benefits stemming from women's participation in soccer. The document called simply "Women's Football" lists the aims that FIFA wishes to achieve with respect to women's soccer. In addition to supporting soccer training at all levels, the document promotes courses for female coaches, referees, and physicians, conferences on women's sports, increasing the number of women holding managerial positions in soccer, developing sports infrastructure for women, and establishing a timetable for women's soccer matches.

One of FIFA's missions is to promote the development of women's football, support women's football financially and give women players, coaches, referees and officials the opportunity to become actively involved in football. FIFA is helping to popularise the game by increasing public awareness and conducting information campaigns as well as overcoming social and cultural obstacles for women with the ultimate aim of improving women's standing in society.

In Poland, only two organizations (PZZ, PZPC) state their willingness to support women's sports. PZB, PZG, and PZHL introduced an entry on supporting both women's and men's sports. However, this entry can be interpreted in two ways. On the one hand, it may be considered as an announcement that the organization pledges to develop the discipline it represents, e.g., "ice hockey in general". On the other hand, it can be presumed that since the entry mentions both women's and men's hockey, the organization will take 
care to promote equal development of both forms of hockey. The entry lacks an explicit statement that because women's sports have been marginalized and trivialized, the organization is going take special care to develop them and thus to balance the chances of women and men.

"The aim of the Federation is to organize, develop, and popularize ice hockey among men and women" (Section 11, Chapter II, Aims and Means of Operation, Statute of PZHL).

"The aims of the Association are:

1) to organize sports competitions in gymnastics and to popularize and develop gymnastic sports, including women's artistic gymnastics, men's artistic gymnastics, and rhythmic gymnastics in Poland" (Aims of the Association and Their Realization, Chapter II, Statute of PZG).

The quoted provisions from the statutes of Polish sports organizations differ greatly from the quoted documents of international organizations. The previously analyzed provisions emphasized the promotion of gender equality as part of the aims of a given organization. As a result, it was obvious that the development of women's sports is the aim of the organization due to the organization's recognition of the equality rule as the driving principle. Polish provisions seem to mention women's sports only as part of the list of disciplines supervised by a given organization. This is especially clear in the statute of PZG.

The situation is different for British sports organizations. Even though, as Table 3 indicates, only FA has provisions on supporting women's soccer, the equality policies of different British organizations extensively comment on the development of women's sports and equal rights.

The documents of these organizations include statements on the development of their respective disciplines regardless of the gender, age, race, or social status of persons involved in sports. These documents also guarantee the fostering of elderly persons' sports, primarily defining discrimination, sexual harassment, stalking, and distressing. They describe direct and indirect discrimination and discrimination by association. They also note that breaking anti-discriminatory rules is liable to prosecution, and that such actions are considered serious infractions. Polish and international sports organizations lack such policies and documents.

\section{Purpose of the Policy}

2.1. BWLA recognises that individuals or certain sections of the community may have been affected by past discrimination and may have been denied the opportunity to participate equally and fully in weightlifting at all levels.

2.2. This policy has been produced to prevent/tackle any potential/ current discrimination or other unfair treatment, whether intentional or unintentional, direct or indirect, which may preclude some people from participating fully in BWLA activities. 


\section{Discrimination, harassment and victimisation}

$B W L A$ recognises the following:

\subsection{Discrimination can take the following forms:}

4.1.1. Direct Discrimination. This means treating someone less favourably than you would treat others in the same circumstances.

4.1.2. Indirect Discrimination. Imposing requirements or conditions, which on the face of it, apply equally to all but which, in practice can be met only by certain sections of the population. Such requirements or conditions are lawful only if they can be objectively justified.

4.1.3. When decisions are made about an individual, the only personal characteristics taken into account will be those which, as well as being consistent with relevant legislation, are necessary to the proper performance of the work involved (Equality Policy BWLA).

The Equality Policy of LTA describes how the organization operates as an employer, what its aims are as the manager of tennis in Great Britain, and what its requirements are concerning every person engaged in issues important for the discipline in Great Britain. LTA guarantees a just recruitment process, audits of the HR departments in terms of equality, introducing equality to the organization's culture as a rule in force, conducting training in equality, thorough consideration of complaints, and the introduction of uniform codes of conduct for cases of infraction to the rules of equality. British sports organizations that have prepared equality policies for athletes engaged in particular disciplines in Great Britain describe their commitments, plans, and undertaken actions in a similar manner.

Some British organizations have also established special bodies (e.g., UKA and $\mathrm{BG}$ ) or persons (e.g., BB) whose role is to address discrimination and foster a gender-sensitive development of sports. These organizations also state in their documents that they take responsibility for adhering to the rule of equality in a given sports discipline in Great Britain.

\section{Implementation Procedures}

6.1. British Gymnastics has developed an over-arching Equality Action Plan, which is designed to increase the diversity of the organisation and its membership. The plan also sets out the actions that British Gymnastics will take to improve our sport, making it more accessible in order to reduce inequalities and under-representation in Gymnastics. The Plan clearly sets out British Gymnastics' commitment to communicating equality with all staff and membership. (Equality Policy BG).

British sports organizations show the highest attention to the rules of equality and emphasize the development of sports for groups that used to be excluded from participation or discriminated against. 
The differences between Polish, British, and international sports organizations are also apparent with respect to disciplinary regulations and established punishments for discriminating behavior. The introduction of discrimination monitoring and punishing discriminatory behavior indicates that these organizations take these issues seriously and recognize how humiliating discrimination is to its victims. Provisions stipulating punishment for discriminatory behavior are difficult to find in the disciplinary regulations of Polish sports organizations. These regulations address many technical matters concerning entry qualifications for competitions or requirements that referees and facilities must meet. However, few provisions concern values that the organizations should promote. Thus, the regulations include general provisions on following "sports rules and ethical norms" (Disciplinary Regulations of PZJ) and statements that breaking the rules stipulated by particular documents is subject to disciplinary action. PZPN is the only analyzed sports organization to create a Soccer Ethical Code listing values, rights, and standards of conduct that persons engaged in soccer should respect. The listed values do not include equality, even though it appears in the preambles to many codes of international organizational and equality policies in British organizations (Code of Soccer Ethics of PZPN).

\section{Ethical Principles in Aquatics}

A. EQUALITY 1. No discrimination on the basis of gender, race, religion, or political opinion shall be tolerated.

B. DIGNITY 2. All forms of harassment, be they physical, psychological, professional or sexual, are strictly prohibited (Code of Ethics FINA).

Unlike Polish sports organizations, the regulations and codes of ethics of international sports organizations draw attention to gender discrimination. The preambles to the codes of ethics, published to present a given organization's official vision in terms of the accepted values, contain a prohibition against gender discrimination and a description of equality as one of the most important rules governing the activity of these institutions. Codes of ethics remove ambiguousness concerning what a given organization finds acceptable. The absence of such codes in the official documents of Polish sports organizations may indicate an inadequate consideration of ethical matters and their effect on the good of all persons engaged in the development of sports.

Most disciplinary regulations of international sports organizations also establish punishment for discriminating behavior. This indicates that the organizations understand the gravity of the issue and empathize with persons who experienced such behavior.

As far as the issue of supporting the development of women's sports is concerned, if any organization recognized the issue, it was usually considered part of the operation of the women's sports committee for a given discipline. Because only two of the analyzed Polish sports organizations have a women's sports committee (PZHL and PZPN), it was difficult to conjecture what actions are planned to support the development of women's sports. The short entry on the aims of the Women's Soccer Committee and the lack of any reference to the Women's Ice Hockey Committee in the documents of PZHL makes it 
difficult to understand the contribution of these committees to the development of women's sports. The PZHL committee is not included in the organization's statute. Consequently, it is unknown whether it is a permanent or temporary committee or whether the need for its existence is acknowledged. In such circumstances, it is probably more difficult to introduce long-term actions.

Nine of the analyzed international organizations have women's sports committees (AIBA, FIBA, IAAF, FIFA, IIHF, FILA, ISF, UCI, and ITF). These committees are permanent and included in the crucial documents of the organizations, which describe the aims of the committees. Notable among the provisions quoted below is the entry from FIBA, which stipulates that before any new member organization is accepted, it must be examined for supporting both men's and women's basketball.

Art. 7. The Women's Basketball Commission has the following duties: a. To study issues relating to women's basketball; $b$. To propose to the Central Board any measures deemed necessary to promote the development of women's basketball; $c$. To propose to the Competitions Commission any measures affecting the official international competitions for women.

Art. 23. Before admitting an applicant federation to membership of FIBA, the Central Board shall satisfy itself that the applicant federation fully controls and governs both men's and women's basketball in its country, and is in good standing in that country (The FIBA Commissions, General Provisions FIBA).

Only one of the British sports organizations, FA, has a women's sports committee. FA also publishes the aims of the committee, which include supporting girls' and women's soccer, creating appropriate legislation, and organizing competitions.

It may seem surprising that British sports organizations have not established more women's sports committees. Other documents published by these institutions, mainly their equality policies, indicate that the institutions understand the marginalization of women's sports and problems related to gender-based discrimination. The fact that appropriate committees have not been created but, at the same time, the fact that documents exist in which the organizations declare acceptance for equal rights may indicate that most members of these organizations are sensitive to the issue of equal rights. This conjecture is supported by the equality policies, which precisely define the scope of actions of individual organizations related to combating gender discrimination and dedicate a considerable amount of space to define discrimination.The aforementioned documents indicate that international organizations take the most care to ensure gender equality. Among the analyzed organizations, it is the international ones that have women's sports committees that foster the development of women's sports. Notable features of disciplinary regulations are penalties for discrimination, and codes of ethics determine the principles of each organization's operation. Among these principles are such values as gender equality and respect to human dignity. The analyzed material also shows that the official documents of Polish sports organizations contain few references to the issue of gender equality. There are few women's sports committees, and disciplinary committees do not list gender discrimination 
among the infractions. Furthermore, Polish organizations do not create codes of ethics.

\section{CONTENT ANALYSIS OF FORMAL REGULATIONS OF SPORTS CONCERNING THE PRESENCE OF PROVISIONS ENSURING GENDER EQUALITY}

Quotas are the most commonly known (and possibly the most controversial) method of increasing the number of women in the decision-making bodies of many social organizations. A quota of $30-40 \%$ is considered to provide a real benefit in a given environment and prevent the tokenization of women. An appropriate number of positions in a given body is allocated to women based on the assumption that without a significant number of women holding important public positions, the culture of sports organizations cannot become equality-based, and the aims and functioning of organizations cannot be reshaped to benefit also women. This is especially true if the environment women aspire toward is traditionally considered masculine, and the culture of a given organization is exceptionally opposed to women. As the research results show, this phenomenon occurs in sports organizations [27, 28].

The results of content analysis concerning Polish sports organizations presented in Table 1 indicate that none of the Polish organizations have rules ensuring positions for women on the Boards of directors, executive committees, or even in women's committees (in those organizations that have it).

Only one of the analyzed international organizations has introduced gender quotas. ISAF has introduced gender quotas in committees, but only at the level of $25 \%$ (of female/male members of the committee) and $20 \%$ (committee vice-chairman/vice-chairwoman).

5.2.2. The Executive Committee shall, subject to any specific provisions in these regulations relating to a particular committee, so far as practicable follow the following guidelines:

(b) not less than $25 \%$ of the members of each committee should be drawn from each gender;

(c) not less than $20 \%$ of the chairmen and vice-chairmen of all committee should be drawn from each gender (Appointment Process, Regulations ISAF, 2013).

These provisions also show that the quotas are not only meant to be advantageous to women, but also meant to ensure appropriate representation to a minority group. ISAF is notable for its entry on publishing strategies concerning the representation of both genders at the general meeting, which indicates that the authorities of the organization recognize the importance of a gender-balanced workplace.

ISAF shall publish from time to time its policy with regard to the representation on Council of the two genders and shall circulate Member National Authorities with the policy at the start of the nomination process (2. Representation On Council, Regulations ISAF, 2013). 
In turn, IAAF has introduced to its constitution an entry stipulating a minimum number of six women holding positions on the Boards of Directors (out of a total of 15 members). This translates to women constituting $27 \%$ of the IAAF Board of Directors, which is an exceptionally good result compared to other analyzed organizations. Admittedly, no positions for women have been allocated for the executive committee, but the existing number of guaranteed positions ensures that women are "visible" at their respective posts and can affect the functioning of the organization (e.g.: Election 26, Constitution IAAF).

The IAAF Constitution also guarantees positions for women in committees: at least three in the Technical Committee and two in other committees, except the Women's Committee, in which men are guaranteed at least two positions. Furthermore, ISAF guarantees two out of seven positions for women as vice-presidents and one position at the general meeting (The Council, ISAF Constitution).

64. The officers of the Federation shall consist of the President, the seven Vice-Presidents (two of whom shall be women), the Treasurer and the Secretary General. They shall be ex-officio members of all committees of the Federation and, save for the Treasurer and the Secretary General, shall be entitled to vote on committees to which they have been appointed by the Council (The Officers, Statute ISAF).

The remaining seven international organizations have provisions guaranteeing single positions for women. While this constitutes a step toward gender balance in sports organizations, women holding single positions will be unable to change the operating strategy of these organizations or to ensure the development of women's sports. This will only help these organizations improve their image as institutions fostering gender equality within their structure. FIBA and IHF allocate two positions for women on their Boards of Directors, and FIFA allocates one. Notably, FIFA assures that if no woman is appointed for the position, it will remain unoccupied. This entry seems significant, not least because of the widespread practice of substituting female candidates for male candidates. FILA's provisions on the subject are limited to the statement that each continental council must include at least one woman. The official documents of FIVB only state that its Board of Directors must include both genders.

Among the analyzed British organizations, only BIH has an entry guaranteeing two positions for women on its Board of Directors. Other British organizations do not have provisions of this kind.

Among all 51 analyzed organizations, only eight have introduced any entry guaranteeing positions for women in their managerial bodies. This may be caused by the controversy that still surrounds quotas and by the fact that implementing such regulations forces a given organization to follow them, preventing avoidance. Provisions on the development of women's sports and equality as a key value or even the prohibition against gender discrimination itself do not effect such a change in the structure of the organization. These provisions result in a much greater number of women entering the organization and the organization looking for female candidates and having to take their opinions into account (assuming, of course, that their number in a given body 
is sufficient). The impact of these provisions is, without a doubt, much greater than that of other provisions. Nonetheless, the structure of the organizations cannot become more inclusive without a growing number of female employees. The small number of organizations that have adopted appropriate provisions shows that a good amount of time is required to change the current state of affairs.

\section{CONTENT ANALYSIS OF FORMAL REGULATIONS OF SPORTS ORGANIZATIONS IN TERMS OF THE LANGUAGE USED}

The analyzed material suggests that no Polish organization uses gendersensitive language in its documents, i.e., no organization uses feminine suffixes or words associated with both women and men. The Polish words for "president", "athlete", and "member" found in the documents clearly denote men. A section of the statute of PZPN, referred to below, references male trainers but not female trainers, male managers but not female managers, male activists but not female activists, etc. The woman does not exist in the documents of Polish sports organizations. Even PZG (Polish Gymnastics Association), the most feminized among all analyzed organizations, uses language biased toward men. A problem arises with the Polish word for "sportswoman", sportsmenka, originally borrowed from English "sportsman". Even though the word denotes a female athlete, because of the men part, it ultimately still references a man.

In contrast to Polish sports organizations, international organizations are relatively sensitive to the issue of language sexism, and they attempt to solve it by declaring in the preambles that any words referring to men also refer to women and vice versa.

b) Words referring to the singular number shall include the plural number and vice versa

c) Words referring to the masculine gender shall also include the female gender

d) Words referring to persons shall include corporate bodies (Interpretation, Statute FIG).

Only four of the analyzed international organizations (IWF, IHF, FILA, and FIS) do not include such declarations in their fundamental documents. Of course, such declarations are meant not only to combat linguistic sexism but also to prevent an interpretation of the rules whereby a given person would be excluded from responsibility based on the argument that the documents did not mention him or her. A declaration of this type allows the creators of a document to safely ignore the context, as frequently, in addition to the fragment referred to above, the document includes many expressions suggesting that it only concerns men. For instance, women who lead committees are sometimes called chairmen instead of chair or chairperson, as is the case for ITF (Lucy S. Garvin as Chairman of the Junior Competitions Committee), or ISAF (Elizabeth Baylis as Chairman of the Match Racing Committee). Among organizations that have the declaration, many do not use feminine forms (UCI, ITF, ISAF, IRB, IIHF, AIBA, FIBA, and FIFA). Two organizations (FIG and IJS) use provisions referring to both genders inconsistently, i.e., parts of the documents use words that are neutral in terms of grammatical gender, while other parts use 
words with the masculine gender. FILA and IWF do not have declarations that masculine words refer to women in their document. Instead, the organizations use words that refer to both genders. IAAF, FINA, and FIVB also consistently follow the rule of referring to both men and women in all their documents.

C. Any accused person is entitled to his/her defense (Art. 30 - Principles of the Sports Justice, Constitution FILA).

Ensuring the occurrence of a particular incident, which the subject of a bet and for which he/she expects to receive or has received any reward (Art. 47 - Participants' betting activities, Constitution FILA).

C 22.5. A person may not serve on the DCRB if he or she has any other responsibilities for FINA (C 22. Doping Control Review Board (DCRB), Constitution FINA).

The presented results indicate that the declaration in the preambles to documents that all masculine words also refer to women does not mean that the main parts of the documents also encompass women. Thus, such a declaration may cause more harm than good in terms of combating linguistic sexism and establishing women in the language, as it may, in some cases, be used to avoid changing texts that create associations specifically with men, and instead to provide a line of defense in the form of a single clause about grammatical genders referring to both men and women.

Analysis of the documents of British sports organizations concerning the use of feminine words brings similar results. Thirteen organizations include the entry that the masculine forms of words also denote women, and only five organizations consistently follow the rule of referring to both genders (BJ, BVE, EH, BIH, LTA). Two of these five organizations do not have provisions on the reversibility of the grammatical gender. Other organizations have created documents that use masculine forms, taking no care to refer also to women.

In the case of an equality of votes, the chair of the meeting shall be entitled to a casting vote in addition to any other vote he or she may have (21. Decision-making at Executive Board meetings, Articles Of Association Of English Volleyball Association Limited).

\section{CONCLUSIONS}

Against international sports organizations, Polish organizations do not recognize the issue of discrimination against women's sports, nor do they implement any appropriate equality policy. Analysis of the documents showed that Polish sports organizations are negligent in terms of combating gender discrimination in sports and the marginalization of women within the organizations. Only the statutes of three organizations (PZB, PZHL, and PZPN) include provisions prohibiting gender discrimination, and only two organizations declare their willingness to promote the development of women's sports. Apart from these cases, the documents do not guarantee positions or quotas for women within the management bodies of the organizations. The language of the documents refers exclusively to men, which may be considered a symptom of linguistic sexism. The lack of any attempts to change 
the current state of affairs prevents the situation of women in Polish sports organizations from improving. The presented data indicate that in order for this state of affairs to improve, the issue of discrimination must be recognized. Complying with the current situation of women is unacceptable. The official documents of British and international organizations emphasize equality and neutrality in their preambles, which shows that the organizations find these values important. The regulations of Polish organizations describe technical matters and refereeing rules. There are no codes of ethics that would indicate the desired behavior and accepted values.

Analysis of official documents in international sports organizations of sports organizations also showed a much greater recognition of issues related to gender equality and the absence of women in managerial positions. The analyzed organizations emphasized the prohibition against gender discrimination, and some of them declared their willingness to support women's sports. Being aware that the current and past social environment has affected the development of women's sports, some organizations include provisions guaranteeing positions for women in key managerial bodies in their documents. Provisions of the latter type are an especially good example of positive action aimed at reducing the disproportion between the number of women and men employed in sports organizations.

Analysis of British organizations yielded contrasting results. The documents of these organizations devote the most attention to prohibitions against gender discrimination. Separate equality policies have been created that define discrimination and list its symptoms, rather than only single provisions in the key documents of a given organization. Furthermore, the organizations publish strategies for combating discrimination and increasing the number of women in sports and sports organizations. This indicates that the organizations are aware of the presence of gender inequality in sports and sports organizations and that gender inequality is an undesirable phenomenon. In contrast to international organizations, most British organizations do not pay due attention to using language in their official documents that would also recognize women. Only one organization (BIH) guarantees positions for women.

\section{REFERENCES}

[1] Pfister G. Women in Sport - Gender Relations and Future Perspectives. Sport in Society: Cultures, Commerce, Media, Politics.2010;13(2): 234-248.

[2] Kay T. Women, sport and gender inequality. In: Houlihan B, editor. Sport and society. A student introduction. London: Sage Publications; 2003, 130-155.

[3] Messner M, Dworkin S. Just do what? Sport, Bodies, Gender. In: Scraton S, Flintoff A, editors. Sport and Gender. A Reader. New York: Routledge Taylor and Francis Group; 2002, 17-29.

[4] Whitson D. Sport in the social construction of masculinity In: Messner M, Sabo D, editors. Sport, men and the gender order. Champaign:Human Kinetics; 1989, 19-30.

[5] Connell R. Messerschmidt J. Hegemonic Masculinity: Rethinking the Concept. Gender Soc. 2000;19(6): 829-859.

[6] Connell R. A thousand miles from kind: Men, masculinities and modern institutions. J Men's Stud. 2008;16(3):237-252.

[7] Hall A. The Discourse of Gender and Sport: From Femininity to Feminism. In: Scraton S, Flintoff A, editors. Sport and Gender. A Reader, New York: Routledge Taylor and Francis Group; 2002: 6-16.

[8] Kim J. Gender inequality in the U.S Labor Market: evidence from the 2000 Census. In: Karsten M, editor. Gender, race and ethnicity in the workplace. Issues and challenges for today's organizations, V.(1), Westport: Praeger Publishers; 2006, 269-290.

[9] Kimmel M, Aronson A. The gendered society reader. New York: Oxford University Press; 2004.

[10] Acker J. Hierarchies, jobs, bodies. A theory of gendered organizations. Gender Soc. 1990;(2):139-158. 
[11] Connell R. Gender: In world perspective. Cambridge and Malden: Polity Press; 2009.

[12] Alvesson M, Billing Y. Understanding gender and organizations. London: Sage Publications; 1997.

[13] Woo D, Khoo G. Corporate culture and leadership: traditional, legal and charismatic authority In: Karsten M, editor. Gender, race and ethnicity in the workplace. Issues and challenges for today's organizations, V(1). Westport: Praeger Publishers; 2000, 79-113.

[14] Powell G, Butterfield A, Parent J. Gender and managerial stereotypes: Have the times changed? In: Karsten M, editor. Gender, race and ethnicity in the workplace. Issues and challenges for today's organizations, V(2). Westport: Praeger Publishers; 2000, 143-163.

[15] Anderson E. The maintenance of masculinity among the stakeholders of sport. Sport Management Rev. 2010;12(1):3-14.

[16] Messner M. Gender ideologies, youth sports, and the production of soft essentialism. Soc Sport J. 2010;28:151-170.

[17] Adams A, Anderson E, McCormack M. Establishing and challenging masculinity: The influence of gendered discourses in organized sport. J Lang Soc Psychol. 2010;29(3):278-300.

[18] Anderson E. "I used to think that women are weak": Orthodox masculinity, gender segregation and sport. Sociol Forum. 2008;23(2):257-280.

[19] Sibson R. "I was banging my head against a brick wall": Exclusionary power and the gendering of sport organizations". J Sport Management. 2010;24(4):379-399.

[20] Hoeber L. Exploring the gaps between meanings and practices of gender equity in sport organization. Gender, Work \& Organization. 2007;14(3):259-280.

[21] Pfister G, Radtke S. Sport, women and leadership: results of a project on executives in German organizations. Eur J Sport Sci. 2009;9(4):229-243.

[22] Pfister G, Radtke S. Dropping out: Why male and female leaders in German sports federations break off their careers. Sport Management Rev. 2006;9:111-139.

[23] Knoppers A. Giving meaning to sport involvement in managerial work. Gender, Work \& Organization. 2010;18(1):1-22.

[24] Krook M. Gender quotas, norms, and politics. Politics \& Gender. 2006;2(1):110-118.

[25] Dahlerup D, editor. Women, quotas and politics. New York: Routledge; 2006.

[26] Mills S. Language and sexism. Cambridge: Cambridge University Press; 2008.

[27] Skirstad B. Gender policy and organizational change: A contextual approach. Sport Management Rev. 2011;12:202-216.

[28] Sartore M, Cunningham B. Explaining the under-representation of women in leadership positions of sport organization: a symbolic interactionist perspective. Quest. 2007;59:244-265. 